\section{La legislación como aspecto de la relación intercultural}

\section{Rodrigo Lillo $V^{\prime}$}

\begin{abstract}
In the presented text, the author attempted to justify the hypothesis of the fact that the important crisis that is perceived in the relationship of the Chilean State and the Indigenous Peoples that inhabit the territory is produced by reason of the perspective that we use to regulate and to explain phenomena of a different cultural and social reality, that is absolutely detactied from this; and that for this purpose, it results illogical to think that could have effective results. In this sense, the current indigenous legislation, damages of with the fact that they have damaged all the previous: thev have been dictated a series of procedures that, under the excuse of solving the "tremendous indigenous issue" have intended on the other hand, to solve a problem ours, as in the shortage of production goods; but not the topic of how we relate ourselves to these who are different. Thus, in spite the good intentions that gave light and sense to the Law 19.253 (Indigenous Law), this is only a reiteration of our legal system regulary the distribution of scarce resources, through the application of the concept of real rights on a saleable goods, according to the definition of "the land" between us. That, in fact. the possibility of solving these conflicts, does not depend on what could adequately that could seem us "our solution" of the problem, but, of the possibility of establishing covenanted and agreed answers. The possibility of acceding to a relationship intercultural more positive, depends in short of up to that point are capable of assuming the autonomy as a value, in the sense of understanding that exist other so valid conceptions as the our of the well; "that each human being - or human group - possesses the capacity of tracing his own life plan, and, in end. of adapting the set of their acts to that plan's.
\end{abstract}

\section{RESUMEN}

En el texto que se presenta se intenta justificar la hipótesis de que la importante crisis que se percibe en la relación del Estado chileno y los Pueblos Indigenas que habitan en su territorio se produce por razón de la perspectiva que utilizamos para regular y explicar fenómenos de una realidad social y cultural distinta, que es absolutamente ajena a ella: y que por lo mismo, resulta ilógico pensar que pueda resultar. efectiva. En este sentido. la legislación indigena actual. adolece del defecto de que han adolecido todas las anteriores: se han dictado una serie de normas que. hajo la excusa de resolver la "fantasmagórica cuestión indigena" han pretendido en cambio resolver un problema muestro, como lo es la escasez de bienes de produción: mas no. el tema de cómo nos relacionamos con quienes son distintos. Asi, pese a las buenas intenciones que dieron luz y sentido a la Ley $N$ " 19.253 (Ley Indigena). esta no viene a ser sino una reiteración de nuestro sistema legal sobre la distribución de los recursos escasos, mediante la aplicación del concepto de los derechos reales sobre una cosa comerciable, según es definida la tierra entre nosotros. Que, en definitiva. la posibilidad de resolver estos conflictos, no depende de lo adecuado que pueda parecernos "muestra solución" del problema, sino, de la posibilidad de establecer respuestas pactadas y acordadas. La posibilidad de acceder a una relación intercultural más positiva', depende en suma de hasta que punto somos capaces de asumir la autonomia como un valor en el sentido de entender que existen otras concepciones tan valederas como la muestra del bien: "que cada ser humano -o grupo humanoposee la capacidad de trazar su propio plan de vida, y; en fin, de adecuar el conjunto de sus actos a ese plan"?

Desde el Acuerdo de Nueva Imperial asistimos a lo que se ha querido denominar cómo una nueva relación entre la sociedad mayor y los pueblos indigenas en nuestro pais. Esto es aparentemente asi, si lo apreciamos desde el punto de vista de la situación juridica anterior a 1993. La propia discusión en el parlamento se dio en los términos del pago de la deuda histórica. En este sentido, y hasta ahora. distintos sectores de la sociedad perciben esta ley como un avance. No obstante, y desde un tiempo a esta parte los conflictos entre los pueblos indigenas y la sociedad mayor. entre grupos étnicos y el Estado parecen multiplicarse y agudizarse. Algo parece no estar funcionando.

Quienes lucharon con fuerza y trabajaron con energía con el objeto de que este conjunto de ideales se transformaran en ley, tuvieron el sueño de que con el decreto promulgatorio del presidente de la República, que aseguraba la vigencia de la nueva ley, se acababa también la "historia de la intolerancia" ${ }^{\prime 4}$ se daba comienzo a una nueva etapa historica en la relación del Estado chileno con los Pueblos Indigenas que aqui habitan.

Desde un punto de vista del contenido ideológico. esta ley, se puede resumir de la siguiente manera : i) el Estado de Chile reconoce la existencia de las etnias (no de los Pueblos Indigenas). Con lo que, podemos afirmar juridicamente, que el nuestro, es un pais pluriétnico. ii) el Estado valora la existencia de esta etnias, porque entiende que forman parte de la historia de nuestra nación, y constituyen los primeros habitantes de su territorio; que además aporta una diversidad a nuestra conformación cultural. iii) el Estado reconoce que la tierra es el fundamento principal de la existencia y cultura de esas etnias. Por último y como forma de realizar estos principios, se establece iv) el deber del Estado y la sociedad, de "respetar, proteger y promover el desarrollo de los indigenas, sus culturas, familias y comunidades, adoptando las medidas adecuadas para tales fines y proteger las tierrats indigenas. velar por su adecuada explotación y su equilibrio ecológico y

\footnotetext{
I Abogado de la Fundacion Instituto Indigena y profesor de la Escuela de Derechos de la Universidad Catoblica de Tenume.

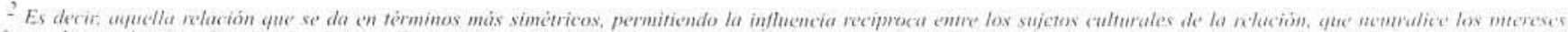
hegemonicus de estos, lo que movocan la elimuacion o sustitucion de un sistema cultural por otro.

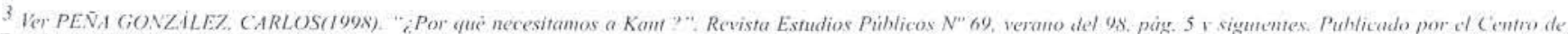

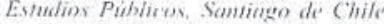

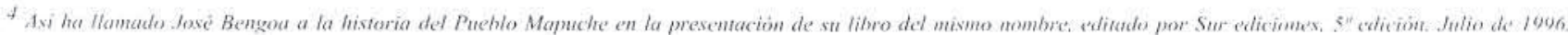


propender a su ampliación " (artículo $1^{\circ}$, Ley $\mathrm{N}^{\circ}$ 19.253).

La protección a que hace referencia el artículo $1^{\circ} \mathrm{de}$ la Ley, se traduce en diversas limitaciones a la libertad de intercambio de bienes, se crea un fondo de tierras, se establecen normas que fomentan la educación intercultural y, en fin, se consagra además la existencia de un órgano que debe velar por el cumplimiento de estos deberes y al que corresponde la coordinación de las políticas públicas respecto de los indigenas. El desafio juridico de dicha creación consistia en poder ensamblar este estatuto juridico especial, que establecia limitaciones al dominio, en un sistema juridico como el nuestro, que dispone un lugar de preferencia para el derecho a disponer de algo arbitrariamente. La pretensión de fondo que plantca esta legislación. en cambio, consiste en hacer coincidir el interés nacional de conservar la diversidad cultural, y el de de desarrollar un sistema económico basado en la propiedad privada y en el libre intercambio de bienes.

La norma parece aprobar -al menos- el examen de constitucionalidad ${ }^{5}$. El hecho de establecer restricciones a un derecho como el de propiedad privada, no significa una negación de esta facultad fundamental. La misma legislación plantea numerosas situaciones de esta naturaleza, en las cuales es posible restringir o limitar un derecho como este, sin pensar por un momento, que se trate de una contradicción. En el amplio marco de los derechos fundamentales, sólo para algunos pocos se reserva la calidad de absolutos (probablemente el derecho a la integridad fisica, establecido para erradicar la tortura. sca una de los pocas excepciones); dentro de las cuales no se encuentra el derecho de propiedad, el cual es concebido más bien como un medio para el logro de otros fines más valiosos como la realización del hombre. De la misma manera, decimos que las limitaciones del artículo 13 de la ley, se encuentran en plena armonia con nuestro ordenamiento juridico, particularmente en los articulos $19 N^{\circ} 23$ y 24 de la Constitución Politica. de cuyas normas, ésta es una excepción prevista. En todo caso, no es posible circunscribir el examen constitucional de la Ley $N^{*} 19.253$ al derecho de propiedad; sería reducir la naturaleza de la Carta Fundamental, a un estatuto del derecho de propiedad privadat.

Ahora bien, el fracaso o éxito de la propuesta de Nueva Imperial, debe analizarse de acuerdo a los objetivos que se tuvieron a la vista; desde esta perspectiva decimos que si lo que se pretendia era establecer una legislación protectora de los indigenas, la ley indigena se presenta como un adecuado instrumento, que sin duda implica un cambio en la situación juridica de los indigenas que habitan territorio chileno.

No obstante, nuestro problema sigue consistiendo en definir ésta relación como una "cuestión indigena"; denominación que parece contribuir aún más a la estigmatización a que hemos sometido a los indigenas durante toda nuestra historia republicana. El tema consiste, mas bien, en cómo logramos abordar una relación equivalente entre Pueblos Indigenas y sociedad nacional. Intentaremos demostrar mediante algunas situaciones reales que se individualizan, que la dificultad para relacionarnos con los que son diferentes, parece ser una dificultad mayor, y que, la insistencia en el voluntarismo de querer imponer nuestras soluciones (por mas pluralistas que nos parezcan). convertirá la salida jurídi- ca, no sólo en una infructuosa; sino que además, se convertirá en un eficaz instrumento de aculturación y devastación de una cultura -tal como ha sido utilizada hasta ahora-.

\section{2.- Paradigma de las leyes indigenas en Chile}

Descle los albores de la República se manifiesta el deseo incontenible del Estado por establecer normas que regularan, no las personas indigenas (respecto de quienes el criollismo ilustrado de la época, no podian establecerse estatutos diversos, so pena de atentar el principio de igualdad), sino respecto de sus Tierras. Para demostrar este aserto baste señalar la ley de 1866, por la cual se entrega al Estado todos los inmuebles baldios y aquellos respecto de los cuales no esté comprobada la posesión efectiva por más de un año, se le faculta para enajenarlos facilitando su colonización. Y que en general, las "leyes indigenas", han sido en realidad leyes sobre las tierras indigenas o sobre las posesiones de los indigenas. Así, la Ley de 1933, establece la prohibición de adquirir tierras indigenas por diez años; Ley N"4169 de 1927, que crea un Tribunal especial cuya función era promover la división de las tierras comunitarias indigenas: Ley $N^{\circ} 4.802$ de 1930 , crea cinco "Juzgados de Indios", que buscaba obtener la división de las comunidades (aún en contra de la voluntad de los comuneros): Decreto Supremo 4111 de 1931, que disponia y regulaba la división de las comunidades indigenas formadas a la luz de las concesiones de merced ; Ley $N$ " 14.511. que regulaba también la división?

Estas leyes, en efecto. han dedicado sus articulados a definir y establecer un estatuto de la tierra indigena; estableciendo restricciones, limitaciones y prohibiciones que -en ocasiones- suponian. la visión de un sujeto inferior e incapaz de administrar sus bienes de una manera "civilizada".

En todo caso. y mas allá de las oscuras o buenas intenciones que pudieron tener los ideólogos y redactores de cada una de ellas, el resultado de la aplicación de esas normas fue persistentemente el mismo: cada nueva ley indigena significó siempre una restricción territorial para los mapuche. Desde la época de la Conquista, luego la Colonia, más tarde la Independencia; luego con el acaecimiento de la ocupación de la Araucania y los posteriores procesos de colonización, y de disputas más o menos violentas con colonos y agricultores; siempre los mapuche fueron perjudicados en su territorio: La historia de este despojo está a la vista. A la llegada de Pedro de Valdivia, los mapuche poseian cerca de 31.000 .000 de hectáreas: mientras a la época de la "Pacificación de la Araucanía", sólo ocupaban 10.000.000 del Bio-bio hacia el sur; en cambio. la tierra entregada a los mapuche con la radicación no ascendia a más de 570.000 hectáreas.

Un intento por asimilar a los mapuche, por la via de la incorporación de sus tierras a los estatutos de la propiedad privada vigentes para la generalidad de los chileno; proceso que. en relación al territorio, comenzó con el despojo, continuó con la reduccion, la asignación de títulos comunes, y pretendió concluir con la conversión de los mapuche en pequeños propietarios y campesinos.

De esta manera. dos procesos se producen de manera paralela y estrechamente relacionados: por una parte la aculturación, por la otra el despojo de tierras. Disminución

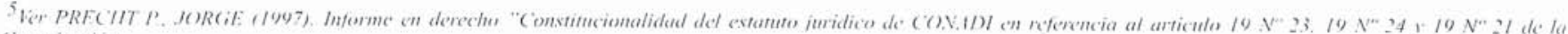
Cinstiution.







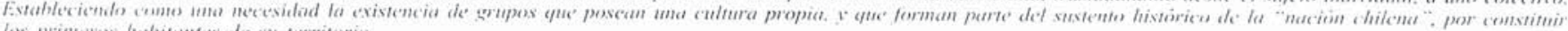
les primeros thathitumfes de su territorie

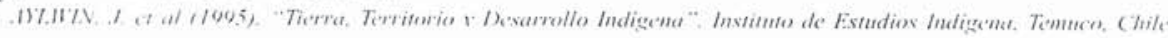


territorial que no tiene como única causa la ocupación militar. En efecto, posterior a la radicación se producirá una proceso de asentamiento de los colonos chilenos y extranjeros en la zona, lo que se hará de manera más o menos violenta, y que significará en todo caso, nueva disminuciones de terrenos. provocados por un sistema jurídico que lógicamente protegia con mayor eficacia a quienes poseian mayores experticias sobre él.

El hecho de por qué el Estado chileno se preocupó de las tierras. puede encontrar una explicación fundada. La campaña militar en la Araucanía de fines del siglo pasado, ha sido explicada en la idea de que no podian existir enclaves en que la soberania del Estado no se hiciera sentir : sin embargo, detrás de ello. habia además una idea de que en la frontera existian tierras fërtiles. útiles para la explotación triguera, que se encontraba en poder de individuos incapaces de aprovechar tales riquezas (los mismos que vertieron su sangre en la bandera. por su resistencia a la conquista española), que nunca podrian obtener una un rendimiento pleno. pues era conocida su conformación inferior, asi como su condición de alcohólicos y perezosos. Todo esto, en pleno desarrollo de la naciente República chilena. Por estas mismas razones es que posteriormente se prefirio al colono. al distribuir la tierras obtenidas como botin de guerras : esta misma percepción del Estado respecto de los mapuche. han motivado en los agentes del Estado (tribunales de justicia. notarios y conservadores, autoridades administrativas), una actitud discriminatoria respecto de los mapuche. propendiendo a su asimilación y/o aculturación.

Sólo avanzada la segunda mitad del siglo podemos encontrar un proceso legislativo distinto, respecto de los indigenas. E1 26 de Septiembre de 1972 se dicta la Ley N"17.729. A través de este cuerpo legislativo se intenta recoger antiguos anhelos de los indigenas que habitan territorio chileno : para ello se realizan en el sur del país algunos Congresos o trawän. El resultado obtenido fue el establecimiento de ciertas normas sobre proteccion de la Tierra, sobre prueba de estado civil de las personas, etc. La Ley $N=17.729$ prácticamente no tuvo vigencia real. sea por el advenimiento del gobierno militar, como por la dictación de los mencionados Decretos Leyes $\mathrm{N}^{\circ} 2.568$ y $\mathrm{N}^{\circ} 2.750$. (on estos decretos culmina el proceso de radicación iniciado cien años atrás. En ellos se disponía la división de las "reservas indígenas", teniendo como meta, la desaparición de todo régimen especial de regulación de las tierras y las personas: propiciando la desaparición -en definitiva- de los pueblos indigenas en Chile.

Esta opción política adoptada por el Gobierno de la época. movilizó nuevamente a los indigenas, así como antes lo hicieron en la Federación Araucana de Aburto Panguilef a principios de siglo. en congresos y asambleas, o en las movilizaciones por Tierra en el ano 69 y principios de los $70^{\circ}$. organizandose en los "centros culturales". formados al amparo de la Iglesia Católica, que en el año 1979 daria lugar a la Asociación (iremial de pequeños agricultores y artesanos $\mathrm{Ad}$ mapu, y a otra serie de organizaciones o referentes que fueron transformando a la sociedad civil mapuche en un importante actor politico en la determinación de su propio destino. Tanto asi. que en el año 1989 muchas de estas organizaciones suscriben. con las fuerzas politicas que apoyaban al entonces candidato. Patricio Aylwin Azócar -a la postre. Presidente de la República- el ya referido Acuerdo de Nueva Imperial. Fruto de este compromiso, nace posteriormente la Comision Especial de Puchlos Indigenas que se aboca al estudio de un proyecto de Ley para que "al fin" se resuelva el "problema indigena".

El proyecto que de este trabajo se obtiene, lo presenta el gobierno al Congreso, en donde resulta modificado de manera importante. Aún asi, este cuerpo legal opta expresamente por la protección de los indigenas, en razón del interés que toda la nación tendría por conservar la tradición de éstas "etnias". Se establecen normas sobre el reconocimiento del estado civil, asociatividad indigenas, normas sobre educacion intercultural, y la creación de "un servicio público. funcionalmente descentralizado, dotado de personalidad juridica y patrimonio propio, sometido a la supervigilancia del Ministerio de Planificación y Cooperación, denominada Corporación Nacional de Desarrollo Indigena (CONADI). Este orrgano es el encargado de canalizar las politicas públicas del Estado hacia los indigenas, y principalmente. "promover, coordinar y ejecutar. en su caso, la acción del Estado en favor del desarrollo integral de las personas y commidades indigenas. especialmente en lo económico, social y cultural y de impulsar su participación en la vida nacional". Todo esto a partir de la idea del pago de la deuda histórica. y fundado además. en el valor expresado, que para el Estado representa la existencia de estos grupos humanos. que comparten rasgos culturales. autoidentificación y la preexistencia respecto del Estado chileno. en su territorio,

No obstante la opción de protección a que adscribe la 19.253, el paradigma desde el que se plantea, no varia un ápice de la evolución histórica legislativa chilena sobre tierras indigenas. En efecto, la protección que se da de las tierras parte desde una perspectiva occidental. imponiendo conceptos como el de propiedad privada. representatividad en la organización, enriquecimiento como úmica forma de desarrollo. etc. Con lo que en delinitiva no soluciona - tha vez más- sino muestro problema de como distribuir los bienes escasos. agregando apenas una variable: uno de los criterios para realizar dicha distribucion tiene que ver con el origen étnico de uno de los actores., Con esto. la "proteccion" que el Estado chileno otorga a los indigenas y a sus tierras resulta reducida en la práctica: en efecto, y según se dira. no parece ser suficiente el hecho de establecer restricciones a la libertad economica de los mapuche y su cjercicio del derecho de dominio, para mejorar la relación intercultural entre nosotros.

\section{3.- La Ley $\mathrm{N}^{\prime \prime} 19.253 \mathrm{y}$ el concepto de Tierra Indigena.}

La ley 19.253. vigente desde 1993. es el producto langible del acuerdo de Nueva Imperial: mientras yue la CONADI. es el órgano del Fstado encargado de velar por su aplicacion. En el articulo 1" de ese cuerpo legal. se manifiesta una declaracion de principios en virtud del cual. el Fstado chileno valora la existencia de estas "etnias". y se compromete -por lo mismo-a dar proteccion a sus ticras, su cultura y propender a la ampliación de aquellas y a su explotación equilibrada: en el entendido que el desarrollo y la reproducción de estas culturas es relevante para la "nación chilena".

Es en este interés de la Nación chilena en el que se funda el articulo 13 de la Ley $N^{*} 19.253$, sobre fomento. protección y desarrollo de los indigenas, que establece la medida de protección de mayor impacto. que el estado establece para proteger las tierras de los indigenas. Precisamente este fundamento es el que dota a la ley indigena de una posición privilegiada dentro del ordenamiento jurídico. En efecto. dentro de nuestro orden juridico, el tema de la nacion y la soberania

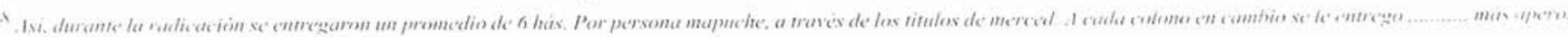
" herramenten
} 
nacional, fic tratado con mucha prolijidad por el constituyente del 80 . El artículo $5^{\circ}$ de la Constitución establece que la soberania reside esencialmente en la nación". cuyo límite lo constituyen los derechos esenciales que emanan de la naturaleza humana. Se establece el deber del Estado de resguardar la seguridad nacional, disponiendo para ello de las Fuerzas armadas y un órgano más novedoso, "el consejo de seguridad nacional", al que le dedica un capitulo completo (capítulo XI de la Constitución Politica chilena).

Además, se establece como uno de los contenidos de la función social de la propiedad (articulo $19 \mathrm{~N}^{\circ} 24$ de la Constitucion Política), incluso antes que la utilidad pública y la conservación del patrimonio ambiental.

Como ha quedado explicado la limitación establecida en el articulo 13 (de enajenación restringida, y gravámenes autorizados previamente por CONADI), no constituye una especificidad que altere la naturaleza del derecho de propiedad tal como se encuentra reconocido entre nosotros; que se aleje por lo mismo del sistema legal chileno. Así. los extranjeros no pueden adquirir el dominio de bienes raices situados en zonas fronterizas (DL 1939 del año $77^{\circ}$ ), tampoco se pueden adquirir los objetos dedicados al culto, por disposición del derecho canónico (a cuya competencia el Código Civil deja dicha regulación), tampoco se permite, por la Ley de Control de Armas, la adquisición de cierto tipo de armas y/o explosivos; no obstante a nadie se le ha ocurrido plantear la inconstitucionalidad de dichas normas, porque corresponden a limitaciones que se encuentran perfectamente incorporadas en el concepto de derecho de dominio recogido por nuestra carta fundamental. En efecto. la concepción del derecho de propiedad entre nosotros, pese a toda la relevancia que tiene. no es absoluto y admite - por cierto- limitaciones. Se concibe el dominio, como un derecho que en si mismo no tiene un valor sino en cuanto constituye un elemento para que el hombre alcance su plenitud. Por esto que el constituyente de 1980. estableció que su límite lo constituia la función social, es decir, que debe ejercerse en armonia con intereses colectivos. La función social esta determinada por el interés de la nación. la utilidad pública, la seguridad nacional, la salubridad pública y la conservacion del patrimonio ambiental.

Las normas relativas a las tierras en la Ley indígena, sólo encuentran su sentido, atendiendo al objetivo planteado. "de protección y fomento y desarrollo de los indígenas", y al carácter de pago de la deuda histórica. Este compromiso sellado por casi la unanimidad de los parlamentarios, da cuenta de una opción tomada por el Estado chileno en esta materia. Dicho de otro modo. las normas de protección de la tierra indigena. constituyen el reflejo de las intenciones expresadas por el legislador. Será necesario entonces, detenerse en el examen de ellas, para comprender el tipo de protección propuesto y su correspondencia con los principios planteados.

Los mecanismos que la ley establece para la protección de la Tierra de los indigenas, son fundamentalmente dos: 1) Ias limitaciones al dominio establecidas en el artículo 13 de la ley; y 2) el Fondo y/o subsidio de Tierras. cuya administración corresponde a la CONADI. El mérito del legislador consiste en haber ensamblado estas normas especiales. en un sistema que aparece a primera vista como contrario a este tipo de restricciones.

1) La primera de estas herramientas es la limitación a la propiedad, prevista en el artículo 13 :

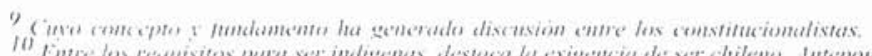



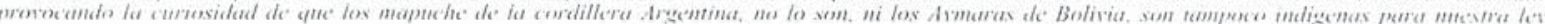

"articulo 13. Las tierras a que se refiere el no podran ser enajenadas, embargadas, gravadas, ni adquiridas por prescripcion, salvo entre comunidades o personas indigenas de una misma etnia."

No es posible entender el contenido de la norma, si no accedemos a dos conceptos que la ley define. Tierra Indigena y Persona Indigena. El concepto de tierra indigena no to entrega la ley, pero si señala, cuales son éstas. De aquí entonces, podremos extraer alguna noción.

\begin{abstract}
"Art. 12. Son tierras indigenas: 1. - Aquellas que personas o communidades indigenas actualmente ocupan en propiedad o posesion provenientes de los siguientes titulos ..... 2.Aquellas que historicamente han ocupado y poseen las personas o comunidades mapuches, aimaras, rapa mui o pascuences. atacameñas, quechuas, collas, kawashkar y vamana. siempre que sus derechos sean inscritos en el registro de Tierras Indigena que crea exta lev; a solicitud de las respectivas comunidades o indigenas titulares de la propiedad. 3.Aquellas que, proviniendo de los titulos y. modos referidos en los nimeros precedentes. se declaren a futuro perteneciente en propiedad a personas o communidades indigenas por los Tribunales de Justicia. 4.- Aquellas que indigenas o sus communidades reciban a titulo gratuito del Estado.....".
\end{abstract}

A su vez el articulo 2" establece quiénes son indigenas, sin -una vez más- definirlos ${ }^{17}$. La terminología usada por el legislador -que parece ser un poco presuntuosa- no debe llevarnos a confusion: lo que la ley indigena protege es -ni más ni menos- la propiedad privada de los indigenas. De esta manera, la ley indigena, sin apartarse ni un ápice de los conceptos ideológicos de nuestro Código Civil, reproduce fielmente los principios de un ordenamiento juridico que encuentra sus bases historicas y políticas muy lejos de La Frontera.

En efecto. la norma del artículo 13 da protección sólo a aquella ocupación mapuche que logre ser acreditada como propiedad, o al menos posesión. en el sentido que la ley chilena da a estas. Esto significará, que la relación existente entre la tierra y el mapuche, debe ser una que responda a lo que el Código Civil chileno define como un derecho real. porque se ejerce directamente sobre una cosa. sin "respecto a determinada persona". Debe ademas ser una que se defina como el derecho del mapuche a disponer de ella (de la tierra) arbitrariamente, no siendo contra ley y contra derecho ajeno. Será por lo mismo necesario, para el mapuche, justificar su tenencia ante el juez de turno, mediante la dualidad titulo modo. que es como se adquiere entre nosotros la propiedad. Se requiere un titulo. es decir, un antecedente que justifique la propiedad o posesion, que la ley indigena restringe a aquellas que señala en el artículo 12, y un modo de adquirir. que se encuentran celosamente enunciados por la ley.

De tal manera decimos que para que un mapuche pueda recurrir a los mecanismos juridicos para proteger su tierra, deben darse al menos dos condiciones: 1) que el antearticulo precedente, por evigirlo el interés nacional. gozarán de la protección de esta ley y. 
cedente, remoto o reciente. de adquisición de la tierra se encuentre en los enumerados por la ley"1, y 2) que el hombre de la tierra exhiba su inscripción practicada en el conservador de bienes raices respectivo.

No bastará que el mapuche ocupe su tierra "de alguna otra mancra", como dice el Convenio 169 de la OIT. Será necesario que el mapuche sea además dueño de la Tierra: que. ademais de la ocupación, justifique alguna relación juridica con esta cosit.

La idea del "nuevo trato" parece esfumarse ante esta explicacion. No sólo, porque estas concepciones y alcances no parecen ni siquiera acercarse a los que emanan de la cosmovision de los indigenas -y en particular, de los mapuche: sino porque además estos mismos instrumentos (aplicados con otra intencionalidad) fueron utilizados para despojarlos de su territorio.

El articulo 13 es entonces absolutamente funcional al orden juridico chileno: pero parece -por oposicion- muy alejado de las concepciones más arraigadas entre los mapuche. Para demostrar esta aseveración, baste recordar que la propiedad privada es una concepción muy antigua, en el pensamiento occidental : consagrada en nuestro Código Civil. que reconoce como antecedentes a su similar francés, de principios del siglo XIX. las leyes de indias, y hasta el derecho romano: y en la Constitución desde 1925. Entre los indigenas. en cambio. la relación del hombre con la tierra no se define segun lo que puedo hacer con ella. No se reduce sólo a lo economico. sino que involucra también lo familiar y lo religioso. Pareciera ser -en verdad- que cualquier relación del hombre con la ticrra no se puede ejercer sino respecto de otra persona: ni parece consistir en un poder total. para gozatr y disponer de clla. hasta incluso destruirla. En cuanto al contenido. la relación con la tierra, parece ser entre los mapuche (y probablemente entre otras naciones originarias de América) de utilizacion temporal, teniendo presente la identificación con ella. mis que el señorio sobre ella. resultando complicado por lo mismo pensar en una relación tan definida y absoluta como la propiedad privada.

El sostener que los mapuche de hoy, conciben y entienden la propiedad como cualquier chileno no-mapuche. no es óbice para señalar que -aún en este caso- no es posible establecer relaciones interculturales simetricas si impongo mis concepciones tradicionales sobre cómo utilizar los recursos naturales. desoyendo los antecedentes culturales del otro.

En otro sentido, decimos que resulta inapropiada esta proteccion. porque el referirse a antecedentes de concesiones otorgadas por el Estado, involucra per se una apreciación profundamente etnocéntrica y de disvalor del otro: "te reconozeo y te cuido en lo que yo te he dado". (En realidad es lo que "te he quitado"). Efectivamente y a la luz de los numerales del articulo 12. no se protege lo que fue el territorio mapuche, sino aquello a lo que. por una politica del Estado, fue siendo sistemáticamente reducido. Así. por la via de la radicación, se les otorgo titulo de merced sobre porciones de tierra. bastante inferiores a aquellos que constituian su espacio de influencia. donde no se ejercia una relación de dominio como la que nosotros conocemos. Desconociendo la naturaleza transhumante de los mapuche. desconociendo también. otro tipo de vinculación con la tierra, distinto al que nosotros conocemos. Luego, también por acción del derecho, vino la división. privándolos de espacios comunes y con la intención de despojarles incluso de su propia identidad.
2) La segunda de las herramientas la constituye el denominado Fondo de Tierras y aguas, regulado en el articulo 20 de la Ley.

"art. 20 Créase un fonde para Tierras 1. Aguas Indigenas "administrado por la comporación. A traves de este Fondo la corporacion podra cumplir con los siguicntes objetivos :

a) Otorgar subsidios para la adquisicion de tierras por personas. Communidades Indigenas o una parte de éstas cuando la suprerficie de las tierras de la respectiva commindad sea insuficiente, con aprobacion de la Corporacion.

Para obresere este subsidion se distinguita enttre postulaciones individuales y de communidades.

Para las postulaciones individuales el puntaje estará dado por el ahorro previo. situacion sociocconomica y gratpo familian:

Para las postulaciones de communidades el puntaje estara determinalo. ademais de los requisitos a la postulacion individual por su antigüedad y mimero de asociades.

Un Reglamente extablecera la firma. condiciones y repuisites de su operatoria.

b) Financiar meramismos que permitan solucionar los problemas de tierras. en especial. con motivo del iumplimiento de resoluciones a transaciones, indiciales a extrajudiciales. relativas a tierras indigenas en que cevistan soluciones sohre tierras indigenas o mansteridas a los indigenas. provententes de los titulos de merced reconocidos por titulos de (o) misario u ofras cexiones o asignaciones hechas por el bistado en faror de los indigenas.

c) Financiar Io anstitucion. regularizacioin o compra de derechos de aguas o financiar obras destimudas a obtencer este recturso. El Presidente ale la Repuiblica, en un reglamento establecerd el mode de operar del fondo de Tierras y Aguas Indigenas".

E1 Fondo de Tierras constiuye un subsidio del Estado. por el cual, y en aplicación del principio de igualdad y del mecanismo de discriminación positiva. se asignan recursos públicos para la adquisición de bienes ráces que tiendan a ampliar la propiedad en manos de los indigenas, mediante dos alternativas: recursos destinados a la compra de predios en conflicto, o que permiten resolver el mismo : y la del subsidio de tierras. Por el primero. se pretende adquirir predios para comunidades cuyas ocupaciones hayan o estén en conflicto en cuanto a su posesión. y se hayan agotado las vias judiciales. Fste subfondo se encuentra pensado en la linea del pago de la deuda histórica y beneficia. en la practica, a comunidades más que a persomas naturales. Por el segundo, en cambio se intenta beneficiar a las personas naturales y corresponde a un aporte del Estado, concursable, a fin de que puedan adquirir hijuelas, de la misma manera como, a través del Ministerio de Vivienda y Urbanismo, se susbsidia la compra de casa habitacionales.

Si bien. el Fondo de Tierras en conflicto. constituye

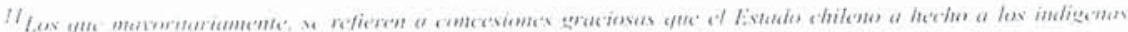

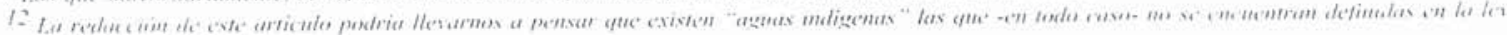


un aporte positivo en el sentido que pretende, su efectividad en el logro del mismo dependerá de las perspectiva con que se plantee su aplicación. En efecto, la modalidad por la que se intenta concretar esta forma de pagar la deuda histórica es a través de la compra de predios; es decir. a través de un negocio entre el Estado y un particular, en beneficio de una comunidad indigena. Ahora bien, como los fondos son (y probablemente lo seguiran siendo) escasos y su administración corresponde a la CONADI. la eficiencia de la gestión de la Corporación en este sentido, será evaluada en tanto cuanto -y conforme a las reglas del mercado- se pague por un terreno. el menor precio por el que los vendedores estén dispuestos a venderlo; y por lo tanto que ese negocio, sea además un "buen negocio". La eficacia del Fondo no puede ser mensurable sólo en relación a esta última circunstancia, quedando en segundo o en tercer plano. la decisión de los propios beneficiados, determinada por una razón histórica, religiosa, una situación de actual ocupación. de opción de desarrollo. 1 otro. De otro modo. con suerte estaremos promoviendo la inserción de los mapuche. en un sistema económico como el nuestro. pero no estaremos otorgando una compensación histórica. si no consideramos siquiera que el objetivo consiste en promover la subsistencia y desarrollo de los indigenas en cuanto tales: y no sólo, en bregar por la superacion de la pobreza. De otra parte, queda claramente establecido que la forma de recuperar tierras, consiste en un negocio, que dependerá de los fondos disponibles y de la eliciente administracion que de ellos haga el servicio público referido. El éxito no puede ser mensurable sólo en relacion a esta última circunstancia. quedando en segundo o tercer plano la aspiración de los propios beneficiados. la relación histórica que exista con la tierra. la situación de actual ocupacion, la actividad económica y forma desarrollo escogida. los aspectos religiosos. etc.

En cuanto al subsidio de tierras mencionado, este no corresponde a un contenido original del proyecto, sino que se trata de uno de los aportes efectuados por los legisladores. Fste subsidio, se aleja, en realidad de los aspectos más profundos de la relación con la tierra propia de la cosmovisión indigena. y parecen responder solamente al antiguo intento por campesinizar a los mapuche: lo que lejos de constituir una forma de fomento. corresponde a un buen intento de asimilacion de los indigenas.

\section{4.- Antecedentes que confirman la hipótesis}

\subsection{La protección del medio ambiente y las comunidades indigenas del cerro Xen Xen.}

En el año 1996. la Empresa Forestal Mininco S.A. incicio un proceso de plantación de árboles exóticos en un inmueble de su propiedad en la comuna de Carawe. denominado Fundo Pancul de alrededor de 170 hectareas. Para proceder a ella previamente se habia producido la deforestación del bosque nativo existente, para luego rozar el terreno y proceder a la plantación. El fundo Pancul. como se denomina, se encuentra ubicado en la parte más alta del cerro Xen Xén. el cual corresponde a las tierras indigenas ancestrales. que posteriormente y durante el proceso de radicación. le fueron entregados titulos de merced a los Lonkos del sector. Durante la primera mitad del siglo, parte del cerro es adquirido por particulares winka. Sin embargo. los mapuche del Xen Xen. no han cesado en su intento por recuperar su territorio, más aun considerando el aleance que liene el Xen $X^{\prime} n$ en la cultura mapuche: que de acuerdo a la leyenda transmitida oralmente a traves de las generaciones. corresponde a la serpiente quc. representando

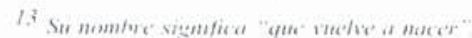

espiritus benignos, permitió la subsistencia del Pueblo mapuche al diluvio iniciado por la serpiente denominada Kai Kai. El Xen Xen tiene un significado de protección para los mapuche. Durante el proceso de reforma agraria. y por aplicación combinada de la Ley Indigena vigente $N " 17.729$ y la de Reforma Agraria N" 16.640) la comunidad intentó recuperar parte del Xen Xen a través de los asentamientos establecidos por dicha ley. Sin embargo en definitiva fracasó el proceso, siendo adjudicado a particulares no mapuche, de los cuales adquirio finalmente la forestal.

Actualmente el Xen Xen es ocupado en la extension de toda su falda por comunidades indigenas, las que deben convivir con la actividad de Mininco S.A. Esta actividad podria provocar un daño fundamental en el terreno de la comunidad. dada la configuración geografica del sector. La deforestacion ha significado la desertificación de los stelos. La plantación de especies exóticas, de conformidad a algunos estudios técnicos de que se dispuso, causaria el agotamiento del agua proveniente de los esteros que nacen del ()ñoicots y que caen por el cerro. lo que afecta la subsistencia de las comunidades. A su ve\% la aplicación de pesticidas quimicos contaminarain el aire y el agua. provocando efectos en los seres humanos que la ciencia no acaba de descubrir. La aplicación de trampas para eliminar algunas especies roedoras y logomorfos, han transtormado el ecosistema de una manera que seguramente transformará la vida de los mapuche del sector. En suma la pretensión de los mapuche consistia influir acerca de las actividades económico productivo a desarrollar en un territorio que consideran propio por motivos -al menoshistórico: y para impedir la depredación de los recursos o elementos que integran tal ecosistema.

l: sistema legal chileno no otorga proteccion a los mapuche de las comunidades del fón Xen. que buscan conservar su territorio. lo que implica a su vez. la preservacion de aquellos elementos que hay se encuentran (como las aves. los insectos. los animales, el agua. la vegetacion) y yue fieron colocados de esa manera por ( han (inceden. por lo que el hombre debe velar por su conservacion. Esto es asi, por cuanto para el ordenamiento juridico. si no disponen de titularidad del dominio. no han adquirido la propiedad, ni poseen parte alguna del Fundo Pancul; no tienen por tanto facultades legales sobre el. ni se trata tampoco de una tierra indigena. solo correspondera a Forestal Mininco S. $\Lambda$. disponer el destino de esas tierras. en atencion al caracter absoluto y exclusivo del dominio. Fl hecho de eonstituir parte de lo que fue su territorio y el deseo de vivir en comunidad. no son limites que puedan oponerse al derecho de dominio.

El orden juridico le permite a los indigenas restringir legalmente la actividad de la lampresa lorestal, utilizando algunas nomas de la Constitución Politica y la Ley de Bases del Medio Ambiente: pero soblo. si concurre alguna hipótesis que permita impedir una actividad economica. si de esto se sigue una degradación grave del medioambiente del sector que pueda poner en peligro o afecte la vida de los seres humanos del lugar. Fn detinitiva. la acción judicial interpuesta fue rechazada por los tribunales. por considerar que los temores de los indigenas correspondian solamente a especulaciones que no se habian materializado en la práctica y no se encontraba acreditado que constiuycran amenazas ciertas a sus derechos, suficientes para paralizar la facna forestal y el ejercicio del derecho de dominio de Mininco S.A. En definitiva se resolvió que. la posibilidad de influencia de los indigenas en el Xen Xen. motivado por su deseo de preservación del ecosistema, no era un bien protegido -en este caso-por el orden juridico, o que de serlo. no tenia mayor fuerza que la del derecho asegurado en el 19) N"24 de la Constitución. 
4.2. La comunidades Pewenches y el uso de las áreas silvestres protegidas.

Es propio de los Pewenche mantener un sistema de transhumancia en virtud del cual (en una actitud que revela la intuitiva tendencia de los mapuche por una actividad económica sustentable), se trasladan durante tres o cuatro meses al año a las zonas cordilleranas más altas. para pastorear sus ganado ovino y bovino y obtener el piñon de la araucaria. Allí se instalan en sus provisorias rukas, "puestos" o "pueblas".

Las comunidades indigenas de Lonquimay fueron divididas. al igual que las otras. En estos procesos se les entregaron titulos de dominio (comunitarios y luego individuales) tanto por terrenos aptos para invernada como suelos de características propias de veranada, que -al igual que en otros lugares- no correspondian al espacio efectivo que ocupaban "de alguna otra manera". No obstante y en algunos casos, hasta hoy, estas veranadas han seguido siendo ocupadas por los pewenche. Constituye una situación de conflicto. el hecho de que un organo administrativo. como la Corporación Nacional Forestal (CONAF) ${ }^{14}$. dispute el uso y aprovechamiento de espacios que han sido declaradas Áreas Silvestres Protegidas (A.S.P.) (sean Parques Nacionales, Reservas Forestales o Monumentos Nacionales, segúm la nomenclatura utilizada por la Ley de Monumentos Nacionales).

En la comuna de Lonquimay existen diversos espacios considerados ASP: Dos reservas forestales, Malalcahuello y Alto Bío bio. La primera se ubica en la precordillera andina, sector "Cordillera de las raices" tiene una superficie de 13.730 hectareas y parte de ellas corresponde a los sectores de veranada de la comunidad indigena de Mallin del Treile. La reserva forestal Alto Bio bio se ubica al sudeste de la ciudad de Lonquimay, abarca 33.050 hectáreas y incluye tierras usadas como veranadas por las comunidades Pewenche Piedra Blanca y Rayen Pehuen. Similar situación se da con los Pewenche que veranean en el Parque Nacional Villarrica y otros ubicados en las comunas de Curarewe y Pucón.

Mientras los Pewenche han concurrido por años a la alta cordillera para recolectar leña, piñon y talaje para sus animales durante tres o cuatro meses al ano, por esta nueva disposicion legal, CONAF ha prohibido a los mapuche el ingreso a esta zona, o en otros casos -como el de Piedra Blanca- les cobra una renta por ello.

Los Pewenche ocupan por mucho tiempo estos sectores. velando por mantener su equilibrio ecológico (cuestion que es propia de la concepción mapuche del universo. en el sentido que el mapu es concebido como un ente vivo. "en que cada elemento juega un rol en la construcción y equilibrio del cosmos"15) actualmente, y mientras el título de dominio se encuentre inscrito en el Conservador de Bienes Raices a nombre del Fisco de Chile y bajo administración de CONAF. los Pewenche no tienen ninguna facultad desde el punto de vista legal. La Corporación Nacional Forestal, a juzgado que los pewenche constituyen agentes depredadores de las especies existentes en estas areas, por los que les ha prohibido su ingreso. Desde el ordenamiento jurídico, sólo se protege el derecho de uso de los pewenche por la vía de acceder a la propiedad de los terrenos, que en este caso sólo ocurrirá. si por voluntad del Estado se accede a la desafectación de los terrenos por la via legislativa: o bien mediante el ejercicio del derecho establecido en el articulo 35 de la Ley N"19.253. En este articulo se establece la obligación del Estado (a través de sus órganos, Servicio Agricola y Ganadero : SACi. Corporación Nacional Forestal : CONAF, CONADI) de disponer la forma en que los indigenas harin uso de estas zonas en las Areas

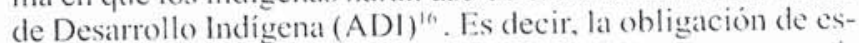
tos órganos de aceptar el uso de las areas silvestres protegidas por los indigenas, sólo cabe en las áreas de desarrollo indigenas que como nos indica la propia ley, se constituyen mediante un Decreto Supremo por voluntad del Presidente de la República. Además la voluntad del Estado chileno ha quedado expresada también, en la suscripción de los " Acuerdos de Rio". que contiene normas (Convenio de Biodiversidad). que postulan las ventajas de entregar la administracion de zonas que compartan estos caracteres, a los Pueblos originarios. En el caso de Lonquimay. el decreto de designación de ADI. tras la dictacion de la Ley indigena, fue el primero en anunciarse, sin embargo hasta hoy, no ha sido dictado. Pareciera que la vigencia y el fortalecimiento de esta Areas de Desarrollo Indigena. pudiera constituir una alternativa a la falta de disposición de tierras por los Pewenche, que les permiticra además plantear la conveniencia del que se les otorgue el uso de las ASP, incluso con fines turísticos.

\section{3.- Comunidades indigenas Loneoyán Grande, Pichi Loncován y Pililmapu y la expansión forestal.}

La hijucla oriente del Fundo Pidenco tiene alrededor de 1400 hectireas $y$ actualmente pertenece a la empresa forestal Bosques Arauco S.A., quien posee titulo inscrito vigente a su nombre en el Conservador de Bienes Ratices de Traiguen. Esta hijucla oriente, que a la época de la reforma agraria pertenecia a don Guillermo Uribe Barra, agricultor de la zona. fue ofrecida por su propietario con fecha 2 de Junio de 1971 a la Corporacion de Reforma $A$ graria para su expropiacion. junto con el fundo Tranaquepe. Parte del Fundo Pidenco fue entregado a una Cooperativa de agricultores mapuche. y con fecha 15 de Julio se publica en el Diario oficial la resolución de expropiación de CORA. Sin embargo, esta resolución no fue inscrita en el conservador de Bienes Raices y posteriormente. durante el régimen militar. en lo que se conoció como la contra reformat. esta situacion fue revertida y por disposición de la misma CORA (03 de Enero de 1975). se dejo sin efecto la resolución expropiatoria con lo que el predio fue devuelto a su anterior dueño. El año 1980. Uribe vendió este predio, el que al cabo de otras dos transacciones. es adquirido por Bosques Aratuco S.A.

En gencral, se puede decir que, de esta manera lix "forestada" la comuna de Malleco. Los predios que no fueron devueltos a sus dueños. se remataron por la CONAl' a muy bajo precio. para que -en defintiva- estas empresas plantaran bajo el fomento o subsidio del Estado, establecido en el DL 701 .

A partir del año 1996 dirigentes de la zona de Lumaco y Purén inician un proceso de organizacion para la recuperación de sus tierras. con miras a restablecer un espacio territorial mapuche. Los mapuche no pudieron recurrir a la Ley Indigena para lograr su aspiracion: Forestal Arauco, poscia actualmente el Fundo, justificando su ocupación en una compraventa (título). que se encuentra inscrito en el Registro de Propiedad respectivo (modo). Lo único que podian esgrimir los comuneros de Pililmapu y Pichiloncoyan era un pasado histórico en que por dos ocasiones (previo a la radicación y

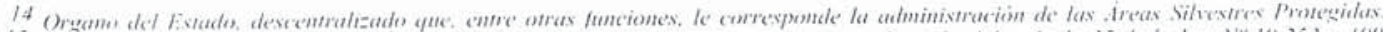

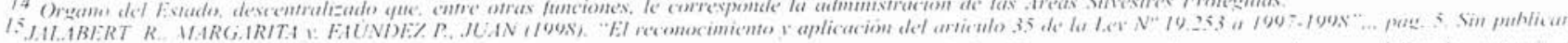

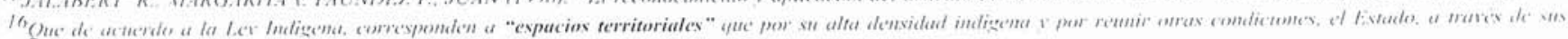

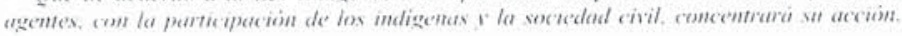


durante el proceso de reforma agraria) esas tierras formaban parte del espacio que ocupaban como su territorio. El fracaso de las comunidades, alentado por la visión parcial de empresarios y autoridades que reiteradamente insistieron en lo que para estos constituia la vigencia del sistema, fomentaron un clima de violencia que terminó con la quema de tres camiones que transportaban madera de la empresa. La reacción política fue la aplicación de la Ley de Seguridad del Estado para doce personas mapuche por delitos contra el orden público: algo que parece estar muy lejos el espíritu de la ley indigena. pero que es la forma que nosotros los winka. hemos utilizado para relacionarnos con las etnias que nos preexisten. Esto es asi, pues dicha reacción no constituye un hecho aislado en nuestra historia. en el pasado reciente. el Gobierno solicitó en el ano 94, un Juer especial para investigar hechos relacionados con movilizaciones indigenas, que culminó con la condena para 140 personas mapuche por usurpación. asociación ilicita y otros delitos.

Muy cerca de alli. la comunidad Lonocoyán Gande, que se formo tras la adjudicación de un titulo de merced al cacique Juan Maril y su familia, dentro del cual ya se exclúan terrenos que hoy forman parte del Fundo forestal El Rincón. Con fecha 30 de Octubre de 1971, en plena época de aplicación de la reforma agraria, titular del dominio del fundo, Sr. Enrique Stappung. hace entrega del mismo al asentamiento "Pelantaro". formado en su mayoria por personas indigenas pertenecientes a la familia de Juan Maril. El 1" de Septiembre de 1972, se publica en el Diario Oficial la resolución expropiatoria de la Corporación de la Reforma Agraria CORA ${ }^{17}$. No obstante, lo anterior. esta resolución nunca se inscribió en el Registro de Propiedad del Conservador de Bienes Raices; por lo que. atendido el sistema de transferencia del dominio entre nosotros, el asentamiento Pelantaro no se hizo dueña del Fundo. Posteriormente. durante el proceso de la contra- reforma la CORA revoca la resolucion expropiatoria, transformandose los mapuche de Pelantaro en meros ocupantes del predio, y los bosques plantados pasan a ser de su dueño, E. Stappung. Por la vía judicial, el antiguo dueño recuperó su posesión sobre el bien, procediéndose al desalojo de los indigenas un dia 26 de Julio del año 1976.

Actualmente el Fundo El Rincón pertenece a la empresa Forestal Mininco S.A., la que al igual que Bosques A rauco S.A.. forestan estos predios subsidiados por el Estado chileno de conformidad a lo establecido en el DL 701. Durante el verano de 1998, mapuche de la comunidad Loncoyán Grande y ex miembros del asentamiento Pelantaro, inician una ocupación en el fundo El Rincón, con el objeto de recuperarlo. Se inicia un diálogo con autoridades de gobierno. Finalmente la CONADI, accede a utilizar recursos del Fondo de Tierras para resolver este conflicto y comprar tierra para la gente de Juan Maril, sin embargo se excluye de plano el predio correspondiente al Fundo El Rincón, por haber manifestado su dueña la negativa rotunda a acceder a una venta para los mapuche que habian ocupado ilegalmente el predio.

Estos dos casos especificos demuestran. que la Ley Indigena en particular, y el ordenamiento juridico en general, no favorece la recuperación ni proteccion de su territorio por los mapuche. Existe sólo un instrumento en la Ley Indígena que se encuentra orientado hacia ese fin, el Fondo de Tierras. No obstante, en un sistema como el nuestro, el proceso de la comunidad esta sometido a la voluntad de la CONADI que debe financiar la compra. con un reducido presupuesto ${ }^{18}$, y del actual ocupante para prestar su acuerdo al negocio.

\subsection{Comunidad Soto Cariqueo y los cementerios indígenas.}

La comunidad indigena Soto Cariqueo habita a $25 \mathrm{~km}$. de la ciudad de Galvarino, en el sector de Alto Ruka Xarü. en la provincia de Cautin. Novena Región. Según relatan las personas más antiguas de la comunidad. esta comunidad disponia del territorio ubicado entre la comunidad de José María Liempi, por el Norte; al Sur, con la comunidad Bartolo Raiman; al Poniente, Mateo Huenchuman; y al Oriente, con el río Rucatraru. Alrededor del año 1937, la comunidad (que en ese entonces era conocida como Pichi Soto Cariqueo) abarcaba unas 1500 hectáreas, que eran ocupadas por unas 40 familias.

En el año 1980, llegó al lugar Juan Abelardo Jeréz. quien ofreció al Lonko sus servicios para proteger a la comunidad de bandidos que asolaban la zona. Por lo que se entregaron dos hectáreas de la comunidad para su subsistencia. Posteriormente, Jeréz y su familia, usurpan a la comunidad más de 100 hectáreas de terreno; las que más tarde, durante el proceso de radicación (1910), no son consideradas para la comunidad. Durante este proceso de radicación, se entregan a la comunidad, bajo título de Merced, unas 282 hectáreas; quedando excluido lo que hasta ahora habia sido su cementerio. En dicho cementerio se encontrarian enterradas unas 40 personas. entre los cuales figuran el antiguo Lonko de la comunidad. y la machi.

El cementerio se encuentra en propiedad de un tercero no indigena, por lo que no puede considerarse Tierra Indigena. A su vez, la Ley Indigena, sólo faculta el uso de cementerios ubicados en predios ajenos a la comunidad. cuando se trata de predios fiscales. A su vez. el Articulo 28 letra c), se remite a la Ley 17.288 , en todo lo que se refiera a las excavaciones de cementerios históricos indigenas.

La Ley 17.288. sobre Monumentos Nacionales reserva para el Consejo de Monumentos Nacionales. la tuicion y protección de "... los enterratorios o cementerios u otros restos de los aborígenes". Este Consejo, es un organismo técnico que depende directamente del Ministerio de Educación. Corresponde al Consejo, entre otras atribuciones, "pronunciarse sobre la conveniencia de declarar Monumentos Nacionales los lugares, ruinas, construcciones u objetos que estime del caso y solicitar... la dictación del decreto supremo correspondiente: gestionar la reivindicación o la cesión o la venta al Estado o la adquisición a cualquier titulo por este, de os Monumentos Nacionales que sean de propiedad particular; conceder los permisos o autorizaciones para excavaciones de carácter histórico..."

Este cementerio no puede utilizarse por ahora, mientras permanezca bajo posesión de un tercero; y para el caso de que el Consejo de Monumentos Nacionales considere del caso designarlo como Monumento Nacional, su administración pasará a este Consejo y su pertenencia al patrimonio cultural de la nación. Mientras no exista una vinculación mayor entre ambas legislaciones, ni mayor participación de los Pueblos Indigenas en estos procesos, no recuperarán el uso, ni menos. la administración o el dominio de los cementerios que fueron ocupados históricamente por los indigenas.

\section{CONCI.USION}

El análisis de como influye una legislación que pretende brindar protección a un grupo determinado. y asume la interculturalidad como un valor, no puede reducirse a un examen exegético de la norma; después de todo. la actividad juridica constituye la realización de actos de habla especifico, y debemos desligarnos del modelo de conocimiento reflexivo, conforme al cual el conocimiento es el resultado de la distancia entre el sujeto conocedor y el objeto por conocer, $y$ al lenguaje como la única forma de representar de manera inteligible. la realidad cática. La idea-dicho de orra manera-que es posible en el proceso cognitivo separar el sujeto que conoce

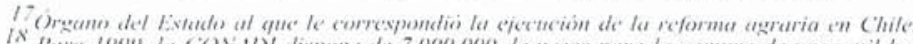

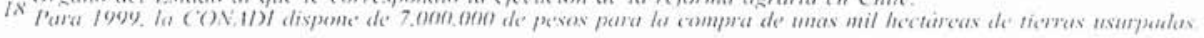


y el objeto del conocimiento, conformando lo que Broekman llama "la aplicación como forma de pensar"l9 :"La acción de aplicar $a$ presupone la separación entre el yo y el mundo, entre el sujeto y el objeto, entre el pensar y el actuar, entre la teoría y la práctica, entre el hecho y la norma, entre el caos y el orden" 20

Diremos acá, más bien, que el derecho no es más que un elemento cultural, y por lo tanto, se debe pensar el derecho como cultura, lo que no implica una visión anárquica o negativa del derecho; significa más bien, no inhibirse del examen de la ideología que se encuentra detrás de una u otra norma o institución. Limitarse al análisis de los instrumentos jurídicos implica sobrediminesionar "una visión racional y voluntarística del contrato social" 21 .

Desde este punto de vista, diremos que la Ley indigena en Chile constituye un adecuado instrumento de protección de los indigenas, en un contexto jurídico/legal como el nuestro. En este sentido, la Ley desde el objetivo que se ha planteado parece acertada; sin embargo, este parece ser precisamente el error en que hemos incurrido permanentemente.

No es posible establecer una relación intercultural simétrica como la pretendida, disponiendo una normativa para los pueblos indígenas, que supone siempre encontrarse en el verdadero y único paradigma, y que a partir de dichos principios se pretenda "proteger al otro". Bajo esta perspectiva, existirá un punto que siempre será incomprensible para los indigenas, como lo es la contradictoria pretensión de proteger a los indigenas mediante un sistema que no ha hecho más que oprimirlos.

Así, las normas dictadas durante el siglo pasado, fueron un intento por legitimar la apropiación de sus tierras; luego, el artilugio para lograr su incorporación a nuestro régimen de administración y al mercado de intercambio; y finalmente, el establecimiento de sistemas, que en la práctica, hicieron frágil su conservación en manos de los indígenas, significaron su división y propugnaron en definitiva la división y su posterior desaparición.

Si para nosotros, las leyes indigenas no ha sido sino un intento por regularizar la propiedad de los indigenas para protegerlos y para integrarlos a la sociedad, este mismo proceso ha sido interpretado por los indigenas como la legalización de "la invasión por la fuerza, la transformación legalizada del sistema de organización mapuche en un sistema occidental, la prohibición de vivir nuestras propias creencias..."

Basta apreciar el inexorable impacto provocado por leyes dictadas "con buenas intenciones", que se tradujo invariablemente en una progresiva pérdida de territorialidad de los indigenas. Por esta experiencia del pasado no parece oportuno caer en la tentación de modificar la ley para corregir la realidad.

No hemos concluido la historia de la intolerancia. Y la explicación de este juicio, puede ser hoy, la misma que antes: mientras nosotros pretendemos "leer" la realidad desde nuestro prisma, e imponer nuestras propias visiones, negando la posibilidad de otras lecturas, parece imposible que podamos convivir con los que son distintos y no intentar su eliminación/asimilación. Dicho de otro modo, parece irrefutable que la legislación indigenista -o sólo indígena- nunca ha resuelto nuestra relación con las primeras naciones, porque bajo la excusa de resolver, una supuesta "cuestión indigena", la ley ha pretendido responder -como se ha dicho- a un requerimiento nuestro, donde los indígenas no son más que un obstáculo. Esta fórmula nunca nos permitirá establecer relación adecuadas con quienes son diversos.
En definitiva parece necesario hacer un adecuado diagnóstico del conflicto; esto implica señalar que no estamos frente a un "problema indigena", no son los indigenas el problema. El problema en definitiva sigue consistiendo, hoy como hace cien años, en cómo se relacionan dos grupo sociales que tiene pasados históricos distintos, que marcan a la vez la existencia de culturas y tradiciones distintas y por lo mismo, una forma de ver, pensar y vivir, muy diferentes (aún cuando tengamos un presente común). Los juristas han obviado esta cuestión por ser indiscutido el paradigma de cómo miramos las cosas y no somos capaces de ponernos en la perspectiva del otro. Por lo mismo mientras intentemos pensar que existe una "cuestión indígena" que se resolverá en cuanto logremos presentar una formula jurídica en que los derechos de los indígenas sean mejor protegidos en un sistema como el nuestro, no estaremos avanzando un solo paso en el desarrollo de una relación intercultural adecuada, marcada por la autodeterminación. Concebido de esta manera, persistirá siempre el dilema de la convivencia con los pueblos originarios. mirada bajo el prisma de la otra. única considerada válida. so pena de ser impuesta por la fuerza.

No resulta relevante en este sentido, la adopción de un sistema que nos parece más o menos protector de los derechos a los indigenas, si no somos capaces de dar un salto cualitativo en el tema de la aceptación de la diversidad.

Se dice que, en el camino de configurar una adecuada relación intercultural se hace necesario por una parte, impugnar la postura según la cual, sólo nuestra visión es verdadera y absoluta; y por otro, valorar aquellos aspectos de la cultura que caracterizan a estos Pueblos Indigenas. En ello, corresponde también un papel al derecho, como un aspecto de la cultura de una sociedad. Asi se hará necesario relativizar aquella visión del derecho omnicomprensible y absolutizante, en la cual sólo existe aquella interpretación de la realidad incorporada en un determinada legalidad. Por otra será, imprescindible escudriñar en los aspectos juridicos y judiciales de los indigenas, que probablemente -como ha ocurrido en lo religioso, en lo ético, en la concepciones de desarrollo, etc.- las naciones originarias tendrán un importante aporte que hacer a nuestras sociedades contemporáneas.

\section{BIBLIOGRAFIA}

- BENGOA . J. (1996). "Historia del Pueblo Mapuche". Ediciones Sur,Santiago de Chile.

- DWORKIN. R. (1989). "Los Derechos en serio". Editorial Ariel derecho, Barcelona, España.

- PEÑA GONZÁLEZ, C. (1981).“"Por qué necesitamos a Kant ?" Revista Estudios Públicos, Chile, $\mathrm{N}^{\circ} 69$, verano del 98.

- AYLWIN, J. et al (1995), "Ticrra, Territorio y Desarrollo Indigena". Instituto de Estudios Indigena, Temuco, Chile.

- PRECHT P., J. (1997). Informe en derecho "Constitucionalidad del estatuto juridico de CONADI en referencia al articulo $19 \mathrm{~N}^{\circ}$ 23, $19 \mathrm{~N}^{\circ} 24$ y $19 \mathrm{~N}^{*} 21$ de la Constitución", Valparaíso.

- JALABERT R., M. y P., J. FAÚNDEZ (1998)"El reconocimiento y aplicación del articulo 35 de la Ley N"19.253 a 1997-1998". Sin publicar.

- BROEKMAN M., J (1993). "Derecho y Antropologia". Editorial Civitas S.A., Madrid, España.

- RAIMÁN HUILCAMÁN, G. (1998). "Perspectivas a la salida del conflicto mapuche". En Seminario "Pueblo Mapuche y Expansión Forestal", Universidad Católica de Temuco

\footnotetext{
19 BROEKMAN, JAN M. (1993), "Derecho y Antropologia". Editorial Civitas. Madrid, Espana; pág. 42 y siguientes.

20 Ob. cit. paig. 43

$2 l O b$, cit., prig. 19

2RAIMAN HUILCAMAN. GALIARINO (1998) "Perspectivas de salida al conflicto Mapuche-forestal". conferencia dictada en el seminario "Puchlo Mapuche y. Expansion Forestal", realizado en la Universidad Catélica de Temuco en elmes de Mavo de 1998. Por puthlicar:
} 